\title{
Evaluation of 3 esterase tests for the diagnosis of subclinical mastitis at dry-off and freshening in dairy cattle
}

\author{
S. A. Kandeel, ${ }^{1,2}$ A. A. Megahed, ${ }^{1,2}$ M. H. Ebeid, ${ }^{1}$ and P. D. Constable ${ }^{2 *}$ \\ ${ }^{1}$ Department of Animal Medicine, Faculty of Veterinary Medicine, Benha University, Kalyobiya, 13637, Egypt \\ ${ }^{2}$ Department of Veterinary Clinical Medicine, College of Veterinary Medicine, University of Illinois at Urbana-Champaign, Urbana 61802
}

\section{ABSTRACT}

Subclinical mastitis (SCM) and intramammary infection (IMI) increase esterase activity in the glandular secretions of dairy cattle. Our objective was to evaluate the clinical performance of 3 commercially available esterase tests for diagnosing SCM and IMI. Foremilk samples were collected from 380 quarters (96 cows) at dry-off and from 329 quarters (83 cows) within 4 to $7 \mathrm{~d}$ after calving. Quarter somatic cell count (SCC) was measured using the reference method (DeLaval cell counter; De Laval International AB, Tumba, Sweden) with SCM defined as SCC >200,000 cells/mL. Bacterial culture of foremilk samples was used to diagnose IMI based on the growth of $\geq 100 \mathrm{cfu} / \mathrm{mL}$. The SCC was estimated using 3 PortaSCC tests (PortaCheck, Moorestown, NJ) from the measured esterase activity and the California Mastitis Test (CMT). Clinical performance was evaluated using logistic regression to determine the area under the receiver operating characteristic curve (AUC) and identify test sensitivity (Se) and specificity (Sp) at the optimal cut-point for diagnosing SCM and IMI. Test agreement was also evaluated using the kappa coefficient $(\kappa)$ and weighted $\kappa$. The PortaSCC color test was the best-performing PortaSCC test for diagnosing $\mathrm{SCM}$ at dry-off $(\mathrm{AUC}=0.90, \mathrm{Se}=0.91, \mathrm{Sp}$ $=0.81, \kappa=0.71)$ and at freshening $(\mathrm{AUC}=0.86$, Se $=0.74, \mathrm{Sp}=0.95, \kappa=0.72)$, at an optimal cut-point of $\geq 250,000$ cells $/ \mathrm{mL}$ but required $45 \mathrm{~min}$ to produce a result. For comparison, the CMT required 2 min to produce a result and a CMT score of trace or higher was superior to the PortaSCC color test for diagnosing $\mathrm{SCM}$ at dry-off $(\mathrm{AUC}=0.95, \mathrm{Se}=0.95, \mathrm{Sp}=0.86$, $\kappa=0.81)$ and freshening $(\mathrm{AUC}=0.88, \mathrm{Se}=0.79, \mathrm{Sp}$ $=0.95, \kappa=0.76)$. The PortaSCC quick test was the best-performing PortaSCC test for diagnosing IMI at dry-off $(\mathrm{AUC}=0.81, \mathrm{Se}=0.81, \mathrm{Sp}=0.78 \kappa=0.40)$

Received December 25, 2018.

Accepted October 16, 2018.

*Corresponding author: constabl@illinois.edu and required 5 min to produce a result, whereas the PortaSCC color test was the best performing PortaSCC test for diagnosing IMI at freshening $(\mathrm{AUC}=0.80$, Se $=0.75, \mathrm{Sp}=0.79 \kappa=0.38$ ). For comparison, the CMT was inferior to the PortaSCC quick test for diagnosing IMI at dry-off $(\mathrm{AUC}=0.73, \mathrm{Se}=0.76, \mathrm{Sp}=0.60$, $\kappa=0.20)$ but was equivalent to the PortaSCC color test at freshening $(\mathrm{AUC}=0.79, \mathrm{Se}=0.58, \mathrm{Sp}=0.93$, $\kappa=0.50)$. The PortaSCC color and quick tests and CMT were considered good tests for diagnosing SCM and IMI because clinically useful tests typically have an AUC $>0.80$ and $\kappa>0.6$. Based on the test sensitivity, cost, and analysis time, there does not appear to be a persuasive reason to select the PortaSCC tests over the traditional CMT for diagnosing SCM and IMI.

Key words: mastitis, DeLaval cell counter, PortaSCC test, California Mastitis Test

\section{INTRODUCTION}

Milk SCC is a commonly used index of udder health in lactating dairy cattle (Constable et al., 2016). An SCC cut-point of $>200,000$ cells $/ \mathrm{mL}$ is defined as subclinical mastitis (SCM) and is widely used to diagnose the presence of inflammation in response to infection (Schepers et al., 1997; Pyorala, 2003; Breen et al., 2009). This SCC cut-point provides adequate sensitivity (0.75) and specificity (0.90) and minimizes the diagnostic error when using foremilk samples to diagnose the presence of an IMI (Schepers et al., 1997; Schukken et al., 2003; Pyörälä, 2003). The California Mastitis Test (CMT) is a rapid, inexpensive, semiquantitative cow-side test that has been used for more than $60 \mathrm{yr}$ to identify quarters with SCM or IMI (Schalm and Noorlander, 1957; Barnum and Newbould, 1961). A range of values for sensitivity (Se) and specificity $(\mathbf{S p})$ have been reported when using the CMT to diagnose SCM or IMI in quarters of dairy cows at various stages of lactation. A CMT result of trace or higher had Se of 0.50 and Sp of 0.73 for diagnosing IMI in a US herd with a high bulk tank SCC (Middleton et al., 2004); Se of 0.87 and Sp of 0.26 for diagnosing IMI in 2 Eng- 
lish herds (Bhutto et al., 2012); and Se of 0.45 and Sp of 0.56 for diagnosing IMI in cows admitted to a US Veterinary Teaching Hospital (Kandeel et al., 2018a). A CMT result of $\geq 1$ had Se of 0.77 and Sp of 0.77 for diagnosing IMI in cows in South Africa (Fosgate et al., 2013). For comparison, a CMT result of $\geq$ trace had Se of 0.57 and Sp of 0.56 for diagnosing IMI on d 3 of lactation in 3 North American herds (Sargeant et al., 2001), and Se of 0.82 and Sp of 0.81 for detecting IMI caused by major mastitis pathogens on $\mathrm{d} 4$ of lactation (Dingwell et al., 2003). Finally, a CMT result of $\geq$ trace had Se of 0.52 and Sp of 0.71 in early-lactation quarters and Se of 0.63 and Sp of 0.53 in late-lactation quarters (Godden et al., 2017). Because of the imperfect test Se and Sp of SCC and the CMT for diagnosing SCM and IMI, as well as the subjective nature of the CMT, there remains a need for new on-farm tests that provide a rapid, practical, inexpensive, and accurate method for diagnosing quarters with SCM and IMI to guide selective intramammary treatment at dry-off and freshening (Godden et al., 2017; Kandeel et al., 2018b).

Mastitis in dairy cattle is accompanied by altered activity of at least 20 enzymes in glandular secretions, including increased esterase activity (Kitchen, 1981). Esterases are classified broadly as cholinesterases (including acetylcholinesterase), carboxylesterases, and arylesterases, with arylesterases being found primarily in blood and plasma (Williams, 1985). Esterases rapidly split ester bonds and are therefore capable of hydrolyzing several compounds. Esterase activity is increased in mastitic milk due to an increase in blood-milk permeability that facilitates the movement of plasma esterase into milk and an increase in the milk leukocyte count, especially granulocytes (neutrophils, eosinophils, basophils) and the azurophilic granules of monocytes (Marquardt et al., 1966). The arylesterase test was investigated extensively in the 1960s as a screening test for SCM and IMI in dairy cattle (Forster et al., 1961; Booth et al., 1965; Marquardt et al., 1966). The method used to measure milk esterase activity at that time was time consuming and required trained personnel and expensive equipment (Marquardt and Forster, 1965; Luedecke et al., 1967). Moreover, esterase activity in milk varied between cows and over a lactation (Forster et al., 1961; Prasad and Newbould, 1968). Esterase activity therefore lost favor as a diagnostic test for SCM and IMI in dairy cattle, and the application of the test was primarily directed for research purposes. The consensus at the end of the 1960s was that measurement of esterase activity did not provide any clinical advantages over measurement of SCC or milk leukocyte count in the diagnosis of mastitis (Luedecke et al., 1967; Prasad and Newbould, 1968).
The PortaSCC test (PortaCheck Inc., Moorestown, NJ) provides a rapid and simple to use diagnostic test for measuring milk esterase activity that utilizes a different dye substrate for esterase, $3-(N$-tosyl-Lalanyloxy)-indol, than other esterase test methodologies (Kutter et al., 1987; Mendler et al., 2010). The new dye forms an intense indigo blue dye when hydrolyzed. The intensity of the dye color in milk is proportional to the esterase activity; consequently, the intensity of the blue color in milk provides an indirect measure of the SCC (Viguier et al., 2009). The PortaSCC test currently exists in 3 versions that are designed to measure esterase activity in bovine milk. The PortaSCC test involves the sequential addition of milk and reagent to a test strip, incubation for a fixed period, and evaluation of the resultant blue color using a color chart or small handheld meter. The manufacturer recommends that the milk sample be tested as soon as possible after milking at a sample temperature between $7^{\circ} \mathrm{C}$ and $35^{\circ} \mathrm{C}$. If that is not possible, the manufacturer recommends refrigerating the milk sample for up to $8 \mathrm{~h}$ and permitting the sample to warm to room temperature before testing. Peer-reviewed publications describing the performance of the PortaSCC test in bovine milk have recently become available (Balaji et al., 2016; Iraguha et al., 2017); however, neither study compared the test's performance with a suitable reference method. We hypothesized that the PortaSCC test would provide a more accurate method for diagnosing SCM and IMI in bovine milk than the CMT. Accordingly, the primary objective of this study was to characterize the clinical utility of 3 PortaSCC tests in diagnosing SCM and IMI in quarter milk obtained at dry-off and at freshening. A secondary objective was to compare the clinical utility of the 3 PortaSCC tests to that of the CMT in quantifying milk SCC. Milk samples were investigated at dryoff and freshening because decisions are made at these time points as to whether intramammary antibiotics should be infused to treat quarters with SCM or IMI.

\section{MATERIALS AND METHODS}

An observational study was conducted using a convenience sample of 124 lactating dairy cattle, 96 of which were sampled during the last week of lactation and 83 that were sampled from 4 to $7 \mathrm{~d}$ postpartum. All methods were evaluated and approved by the Institutional Animal Care and Use Committee at the University of Illinois at Urbana-Champaign. The study reported here was part of a series of studies investigating the diagnosis of SCM and IMI in lactating dairy cattle. Additional results have been published elsewhere (Kandeel et al., 2017, 2018b). 


\section{Animals, Housing, and Milking}

The study was performed at the University of Illinois Dairy Research Farm over a period of 13 mo between July 1, 2015, and July 31, 2016. The mean number of cows in the milking herd during the course of the study was 136. However, due to workload constraints and occasional delays in obtaining the different PortaSCC tests, quarter samples for analysis were obtained from 117 cows, including 96 cows at dry-off and 83 cows at freshening. Cows in late lactation were housed in a freestall barn. Fresh cows were kept in a tiestall barn after calving until they recovered from any postpartum health issues before being moved to the freestall barn. Cows housed in the freestall barn were milked twice daily at dry-off in a milking parlor at 0400 and $1600 \mathrm{~h}$, whereas cows in the tiestall barn were milked 3 times daily after calving at 0500, 1400, and $2130 \mathrm{~h}$.

\section{Experimental Methods}

The farm was visited at least once a week to collect foremilk samples from each quarter in the same week of dry-off and at 4 to $7 \mathrm{~d}$ postpartum (to exclude colostral milk). Cows at dry-off were moved to a shaded area of the freestall and restrained with the aid of a halter. Foremilk samples were collected between 1200 and $1600 \mathrm{~h}$ for cows at dry-off ( 8 to $12 \mathrm{~h}$ after milking) and between 1200 and $1400 \mathrm{~h}$ for fresh cows (7 to $9 \mathrm{~h}$ after milking). Two investigators (SAK, AAM) wearing disposable gloves were involved in foremilk collection and situated on either side of the animal. The teat end of each quarter was cleaned with $70 \%$ alcohol, and 20-mL milk samples were collected separately into sterile polypropylene tubes within $50 \mathrm{~s}$ of first touching any teat, by hand stripping after discarding the first 3 squirts of milk. This sampling method ensured that the samples were gland cistern samples and not mixed samples with variable amounts of alveolar milk (Sarikaya and Bruckmaier, 2006). A physical examination was then performed on each cow to identify the presence of any systemic disorder. Udder and milk were examined by palpation and inspection, respectively, to detect the presence of abnormalities indicative of clinical mastitis. One investigator (SAK) was responsible for all evaluations and analyses.

The CMT was performed beside the cow according to Schalm and Noorlander (1957). Two milliliters of fresh foremilk sample from each quarter was added to the corresponding chamber of the CMT plastic paddle and mixed with $2 \mathrm{~mL}$ of CMT reagent by gently moving the paddle in a circular motion. The volumes were estimated visually, reflecting typical testing practices when the CMT is applied cow-side. A change in viscosity indicates an increase in the DNA content (and therefore SCC) of the milk. The CMT reaction was visually scored at $45 \mathrm{~s}$ after adding the reagent using a 5-point scale (negative, trace, 1 positive, 2 positive, 3 positive).

The milk samples were placed in iced water in an insulated container and transported to a laboratory at the dairy where SCC for each quarter milk sample was directly measured using a DeLaval cell counter (DCC, DeLaval International AB, Tumba, Sweden). The DCC is a portable fluorescent counter designed for the rapid and direct measurement of milk SCC. Approximately $1 \mu \mathrm{L}$ of milk was automatically aspirated into a small disposable cassette and stained with propidium iodide, which fluoresces when bound to DNA. The cassette was then inserted into the DCC and the SCC measured within $45 \mathrm{~s}$. The DCC method has been validated for bovine milk at $4^{\circ} \mathrm{C}$ and $37^{\circ} \mathrm{C}$ against the Fossomatic (Foss, Hillerød, Denmark) and direct microscopic methods (Sarikaya and Bruckmaier, 2006; Malinowski et al., 2008; Kawai et al., 2013; Hanuš et al., 2014) and was used as the reference method in the study reported here. The DCC method has a measurement range of 10,000 to $4,000,000$ cells/mL and the manufacturer reports repeatability (coefficients of variation) of $12 \%$ at 100,000 cells $/ \mathrm{mL}$ and $8 \%$ at 400,000 cells/mL.

After transportation to the laboratory in iced water in an insulated container, the SCC was measured on quarter milk samples using the 3 versions of the PortaSCC test. All 3 versions of the PortaSCC test use a test strip that contains several novel membrane layers and a dry reagent system. A chemical reaction between the dye on the test strip and esterase in the milk changes the test strip to a blue color, with the color intensity being proportional to the amount of esterase present, which is associated with the SCC. The PortaSCC test is available in 2 versions: the original PortaSCC color test that is read qualitatively using a color chart or quantitatively by a digital reader and the more recently developed PortaSCC quick test. Both tests use the same technology but differ in the amount of milk and reagent used and the incubation period.

Transported quarter milk samples were placed in a water bath at $37^{\circ} \mathrm{C}$ for at least $20 \mathrm{~min}$ and thoroughly mixed. All 3 PortaSCC tests were performed according to the manufacturer's recommendations except that the milk sample temperature was approximately $37^{\circ} \mathrm{C}$ when tested to reflect potential use as a cow-side test (the recommendation was to use milk samples at 7 to $35^{\circ} \mathrm{C}$ ). Running the test with milk samples at $37^{\circ} \mathrm{C}$ was considered unlikely to negatively affect the measured value because esterase activity is higher in milk at $37^{\circ} \mathrm{C}$ than at $32^{\circ} \mathrm{C}$ or $23^{\circ} \mathrm{C}$ (Marquardt et al., 1966). The PortaSCC color test was performed using the pipette provided with the test kit; 1 drop of well-mixed milk 
was added to the test strip sample well and 3 drops of activator solution were subsequently added to the strip. The SCC value was measured 45 min later using the color chart provided by the manufacturer. The color chart for the milk test provided 6 SCC categories: $\leq 100,000,250,000,500,000,750,000,1,500,000$, and $\geq 3,000,000$ cells $/ \mathrm{mL}$; the first and last values represent cutoff values, whereas the 4 intermediate values represent the midpoint of the range.

Color was also measured using a digital reader that calculates the SCC using a proprietary algorithm depending on the intensity of the blue color on the test pad. The reader provides a value when the measured SCC is between 50,000 and 3,500,000 cells $/ \mathrm{mL}$ but registers "LO" when the SCC is $<50,000$ cells $/ \mathrm{mL}$.

The PortaSCC quick test was performed using the pipette provided with the test kit; 3 drops of well-mixed milk were added to the test strip sample well, with each drop being added once the test strip had absorbed the previous milk drop. Four drops of activator solution (a total of $\sim 160 \mu \mathrm{L}$ ) were subsequently added to the strip. The SCC value was measured 5 min later using the color chart provided by the manufacturer; the digital reader was not used in the quick test. The color chart for the quick test provided the same 6 SCC categories as for the PortaSCC color test. The manufacturer reported the coefficient of variation for the PortaSCC quick test to be $15 \%$ at 400,000 cells $/ \mathrm{mL}$.

Milk culture was performed based on National Mastitis Council recommendations (NMC, 1999). Blood agar (tryptic soy agar with 5\% sheep blood; Remel, Lenexa, KS) and MacConkey plates (Remel) were divided into 2 equal halves and labeled with the cow ID and quarter. Using a pipette and sterile pipette tips, a $0.1-\mathrm{mL}$ aliquot $(100 \mu \mathrm{L})$ of each quarter foremilk sample was placed on one-half of the blood agar and MacConkey plates separately and then streaked using a sterile wire loop in a manner that allowed the growth of isolated bacterial colonies. Streaked plates were incubated at $37^{\circ} \mathrm{C}$ for $48 \mathrm{~h}$ and microbial growth was recorded. The isolated pathogen was identified by colony morphology; hemolysis pattern; biochemical tests, including catalase and coagulase tests; and Gram staining reaction and cell morphology according to National Mastitis Council guidelines (NMC, 1999).

Matrix-assisted laser desorption/ionization timeof-flight mass spectrometry (MALDI-TOF MS) was applied to isolated colonies to assist in identification to the genus or species level. A thin film of the fresh biological material (a single colony not more than 24 $\mathrm{h}$ old) was smeared directly onto a cleaned MALDI target (MSP 96 polished-steel target; Bruker Daltonik, Bremen, Germany) using clean sterile toothpicks. Each sample spot was overlaid with $1 \mu \mathrm{L}$ of $70 \%$ for- mic acid to assist in cell disruption, allowed to dry at room temperature, overlaid with $1 \mu \mathrm{L}$ of matrix solution ( $\alpha$-cyano-4-hydroxy-cinnamic acid diluted in $50 \%$ acetonitrile and $2.5 \%$ trifluoroacetic acid), and left to dry at room temperature. The MALDI target was then inserted into a MALDI-TOF MS (MBT-RUO Microflex LT/SH, Bruker Daltonics, Billerica, MA) and operated in the linear mode and equipped with a 337-nm nitrogen laser using FlexControl 3.3 software (Bruker Daltonik). Two hundred forty laser shots were used to generate each spectrum for the classification process, and a mass spectrum over the range of 2,000 to $20,000 \mathrm{~m} / \mathrm{z}$ was collected. Spectra were analyzed with MALDI Biotyper 2.0 software (Bruker Daltonik) using a reference library and an integrated pattern-matching algorithm.

An IMI was defined as isolation of at least one mastitis pathogen from the quarter milk sample at $\geq 100 \mathrm{cfu} /$ $\mathrm{mL}$, equivalent to the presence of 10 or more colonies per plate from the $100-\mu \mathrm{L}$ inoculum. This definition of an IMI was based on a detailed analysis of culture results of a single milk sample (Dohoo et al., 2011) and the results of a recent study that indicated this definition was suitable for defining the diagnostic performance of a new mastitis test (Godden et al., 2017).

\section{Effect of Sample Temperature}

The effect of sample temperature on the 3 PortaSCC tests value was investigated using 15 randomly collected 20-mL composite milk samples obtained from Holstein-Friesian cows during milking in the parlor. The temperatures of the composite milk samples were equilibrated to approximately $4^{\circ} \mathrm{C}, 20^{\circ} \mathrm{C}$, and $37^{\circ} \mathrm{C}$ by placing the samples in the refrigerator, at room temperature, or in a water bath at $37^{\circ} \mathrm{C}$, respectively, for $30 \mathrm{~min}$. The reagent solution was equilibrated to approximately $20^{\circ} \mathrm{C}$ by placing the solution at room temperature. The 3 PortaSCC tests were then run as previously described.

\section{Statistical Analysis}

Statistical analyses were performed using MedCalc statistical software (version 15.11.4, 2015; MedCalc Software bvba, Ostend, Belgium) and SAS software (version 9.4; SAS Institute Inc., Cary, NC); $P<0.05$ was considered significant. A minimum sample size of 300 quarters at dry-off and freshening was identified as a goal based on what was logistically possible due to time and resource constraints balanced against the need for an adequate number of quarters to satisfactorily evaluate the diagnostic test performance of a new test for SCM or IMI. The small number of DeLaval SCC and PortaSCC reader measurements that ex- 
ceeded the upper value for the measurement interval $(4,000,000$ and $3,500,000$ cells $/ \mathrm{mL}$, respectively) were assigned that value (i.e., the samples were not diluted and reanalyzed).

Spearman correlation coefficients $\left(\mathbf{r}_{\mathbf{s}}\right)$ were calculated between the 3 PortaSCC test methods, the CMT (assigning a score of 0 to a negative result; score of 0.5 to trace 1 to $1 ; 2$ to 2 ; and 3 to 3 ), and the SCC. PortaSCC reader values below the lower value of the measurement interval $(50,000$ cells $/ \mathrm{mL})$, as indicated by a display of "LO" by the reader, were assigned a value of 50,000 when calculating the Spearman correlation coefficient. Spearman correlation coefficients were used because the PortaSCC color test, PortaSCC quick test, and CMT score were ordinal variables and because minimum and maximum SCC values existed for the 3 PortaSCC tests and the reference method.

Passing-Bablok regression was used to evaluate the linear relationship between the $\log _{10}(\mathrm{SCC})$ measured by the PortaSCC reader and the reference method. For Passing-Bablok regression, the intercept value reflects constant bias and the slope reflects proportional bias (Passing and Bablok, 1983). Agreement was also examined using Bland-Altman difference plots using the percentage difference in the $\log _{10}(\mathrm{SCC})$ relative to the geometric mean of the 2 measurements. The upper and lower limits of agreement were calculated from the bias $\pm 1.96 \times \mathrm{SD}$; the bias estimate from Bland-Altman plots reflects the mean bias over the range of measured values and therefore includes both the constant and proportional bias identified using Passing-Bablok regression. PortaSCC reader values below the lower value of the measurement interval $(50,000$ cells $/ \mathrm{mL})$, as indicated by a display of "LO" by the reader, were not included in the Passing-Bablok regression procedure or paired $t$-tests (Bland-Altman plots); however, their associated SCC values were depicted graphically. Exclusion of "LO" values from the Passing-Bablok regression procedure was required because this analytical method assumes a constant ratio of variance between the 2 measurements and that measurement errors in both methods have the same distribution (Bilić-Zulle, 2011). Based on the imperfect measurement accuracy of the reference methodology and resolution of the PortaSCC reader, we assigned a range of $25 \%$ as an a priori acceptable limit of agreement for $\log _{10}(\mathrm{SCC})$.

Binary logistic regression (PROC LOGISTIC) was used to characterize the relationship between SCM as determined by the reference method $(1=\mathrm{SCC}$ $>200,000$ cells $/ \mathrm{mL} ; 0=\mathrm{SCC} \leq 200,000$ cells $/ \mathrm{mL}$ ) or IMI as determined by milk culture $(1=\geq 100 \mathrm{cfu} / \mathrm{mL}$; $0=<100 \mathrm{cfu} / \mathrm{mL})$ and the SCC measured by the 3 PortaSCC tests, or the CMT score at dry off and at freshening. PortaSCC reader values below the lower value of the measurement interval $(50,000$ cells $/ \mathrm{mL})$ were assigned the value of 50,000 for logistic regression. The adequacy of the logistic regression model fit was evaluated using plots of deviance influence statistics against the predicted values (Hosmer and Lemeshow, 1989). Receiver operating characteristic curves were constructed for each logistic regression model and the area under the curve (AUC) calculated as a global index of test performance; AUC values for curves $>0.9$ typically indicate a highly accurate test, whereas AUC values of 0.7 to 0.9 indicates moderate accuracy, 0.5 to 0.7 low accuracy, and 0.5 represents a chance result (Swets, 1988). Sensitivity and specificity were calculated at the optimal cut-point of the receiver operating characteristic curves determined by the Youden index (the cut-point where the following expression has its maximum value: $\mathrm{Se}+\mathrm{Sp}-1$ ), which equally weights Se and Sp. The positive likelihood ratio $(+\mathbf{L R})$ was calculated as follows: $+\mathrm{LR}=\mathrm{Se} /(1-\mathrm{Sp})$; values $>10$ indicate that a positive test is good at ruling in a diagnosis such as SCM (Grimes and Schulz, 2005). The kappa coefficient ( $\boldsymbol{\kappa}$ ) was calculated at the optimal cutpoint to characterize the level of agreement between the tests (PROC FREQ). Weighted $\kappa$ were calculated using Fleiss-Cohen weights to characterize the level of agreement between the PortaSCC color test and PortaSCC quick test, between the PortaSCC reader and the PortaSCC color test, and between the PortaSCC reader and the PortaSCC quick test; for the latter 2 comparisons the 6 categories for the PortaSCC reader were $\leq 100,000,100,001$ to $\leq 375,000,376,000$ to $\leq 625,000$, 626,000 to $\leq 1,125,000,1,125,001$ to $\leq 2,250,000$, and $>2,250,000$. Values for $\kappa<0.2$ indicate poor agreement, whereas $0.2<\kappa<0.4$ indicates fair agreement, $0.4<$ $\kappa<0.6$ indicates moderate agreement, $0.6<\kappa<0.8$ reflects good agreement, and $\kappa>0.8$ indicates excellent agreement (Landis and Koch, 1977). Agreement charts (Bangdiwala and Shankar, 2013) were constructed to compare the 3 PortaSCC tests using the 6 categories for SCC.

The effect of milk sample temperature on the PortaSCC result was evaluated using Fisher's exact test (PROC FREQ) for the PortaSCC color and quick tests and mixed models analysis (PROC MIXED) for the PortaSCC reader $\log _{10}(\mathrm{SCC})$ using an unstructured correlation matrix based on the lowest value for Akaike's information criterion.

\section{RESULTS}

Quarter milk samples were obtained at dry-off from 96 animals (9 of which were primiparous), comprising 85 Holstein-Friesian, 7 Jersey, 2 Ayrshire, 1 Brown Swiss, and 1 Milking Shorthorn. The PortaSCC quick 
Table 1. Prevalence of pathogens isolated from 96 dairy cows at dryoff (380 quarters, 4 blind quarters) and 83 dairy cows at freshening (329 quarters, 3 blind quarters) over a 13-mo period

\begin{tabular}{|c|c|c|c|c|}
\hline \multirow[b]{2}{*}{ Pathogen } & \multicolumn{2}{|c|}{ Dry-off } & \multicolumn{2}{|c|}{ Freshening } \\
\hline & $\mathrm{n}^{1}$ & $(\%)$ & $\mathrm{n}^{2}$ & $(\%)$ \\
\hline Aerococcus spp. & 0 & 0.00 & 1 & 0.30 \\
\hline Bacillus spp. & 1 & 0.26 & 2 & 0.61 \\
\hline Brevibacterium spp. & 0 & 0.00 & 1 & 0.30 \\
\hline Candida spp. & 0 & 0.00 & 7 & 2.13 \\
\hline Corynebacterium spp. & 3 & 0.79 & 8 & 2.43 \\
\hline Enterobacter spp. & 1 & 0.26 & 1 & 0.30 \\
\hline Enterococcus spp. & 1 & 0.26 & 2 & 0.61 \\
\hline Escherichia coli & 0 & 0.00 & 1 & 0.30 \\
\hline Klebsiella spp. & 1 & 0.26 & 0 & 0.00 \\
\hline Lactococcus spp. & 8 & 2.11 & 1 & 0.30 \\
\hline Macrococcus spp. & 0 & 0.00 & 1 & 0.30 \\
\hline Micrococcus spp. & 0 & 0.00 & 1 & 0.30 \\
\hline Mycobacterium spp. & 1 & 0.26 & 2 & 0.61 \\
\hline Other staphylococci & 37 & 9.74 & 33 & 10.03 \\
\hline Pseudomonas spp. & 1 & 0.26 & 3 & 0.91 \\
\hline Serratia spp. & 2 & 0.53 & 2 & 0.61 \\
\hline Staphylococcus aureus & 2 & 0.53 & 1 & 0.30 \\
\hline Streptococcus dysgalactiae & 1 & 0.26 & 0 & 0.00 \\
\hline Streptococcus uberis & 0 & 0.00 & 1 & 0.30 \\
\hline Wautersiella falsenii & 0 & 0.00 & 1 & 0.30 \\
\hline Not identified & 6 & 1.60 & 16 & 4.90 \\
\hline Contaminated $^{3}$ & 1 & 0.26 & 1 & 0.30 \\
\hline No growth & 314 & & 233 & \\
\hline
\end{tabular}

${ }^{1}$ Includes 13 quarter samples that contained 2 types of organisms.

${ }^{2}$ Includes 12 quarter samples that contained 2 types of organisms.

${ }^{3}$ Quarter samples that contained $\geq 3$ types of organisms.

test was run on samples from only 56 cows because of delays in obtaining the test. The median SCC measured by the SCC at dry-off (380 quarter samples, with 4 cows having one blind quarter) was 364,000 cells $/ \mathrm{mL}$. Cows were a median of 320 DIM at dry off, and the quarter prevalence of SCM at dry-off, defined as SCC $>200,000$ cells $/ \mathrm{mL}$, was $70 \%$ (265/380).

Bacteriologic culture results at dry-off were available for 379 quarters (1 quarter sample was considered contaminated). The IMI prevalence at dry-off, defined as $\geq 100 \mathrm{cfu} / \mathrm{mL}$ on a quarter basis, was $14 \%(53 / 379)$. Coagulase-negative staphylococci were the most commonly isolated mastitis pathogen at dry-off (Table 1).

Quarter milk samples were obtained at freshening from 83 animals (9 of which were primiparous), comprising 74 Holstein-Friesian, 7 Jersey, 1 Ayrshire, and 1 Brown Swiss. The PortaSCC quick test was run on only 67 cows because of delays in obtaining the test. The median SCC measured by the SCC at freshening (329 quarter samples, with 3 cows having one blind quarter) was 130,000 cells $/ \mathrm{mL}$. The quarter prevalence of SCM at freshening, defined as SCC >200,000 cells/mL, was $35 \%(116 / 329)$.

Bacteriologic culture results at freshening were available for 328 quarters (1 quarter sample was considered contaminated). The IMI prevalence at freshening, defined as $\geq 100 \mathrm{cfu} / \mathrm{mL}$ on a quarter basis, was $23 \%$ (74/328). Coagulase-negative staphylococci were the most commonly isolated mastitis pathogen at freshening (Table 1).

\section{Methods Comparison of SCC Measurements}

The Spearman correlation coefficients for the association between SCC measured by the reference method and the 3 PortaSCC tests were highest for the PortaSCC color test in dry cows $\left(\mathrm{r}_{\mathrm{s}}=0.82\right)$ and fresh cows $\left(r_{\mathrm{s}}=0.75\right.$; Table 2$)$. For comparison, the CMT

Table 2. Spearman correlation coefficients (no. of quarters for comparison in parentheses) ${ }^{1}$ among variables of interest for 96 dairy cows at dry-off (380 quarters, 4 blind quarters) and 83 dairy cows at freshening (329 quarters, 3 blind quarters $)^{2}$

\begin{tabular}{|c|c|c|c|c|c|}
\hline Variable & $\begin{array}{c}\text { DeLaval } \\
\text { SCC }\end{array}$ & $\begin{array}{l}\text { PortaSCC } \\
\text { color }\end{array}$ & $\begin{array}{l}\text { PortaSCC } \\
\text { reader }\end{array}$ & $\begin{array}{c}\text { PortaSCC } \\
\text { quick }\end{array}$ & $\begin{array}{c}\text { California } \\
\text { Mastitis Test } \\
\text { (CMT) }\end{array}$ \\
\hline \multicolumn{6}{|l|}{ Dry-off } \\
\hline DeLaval SCC & 1.00 & $0.82(380)$ & $0.67(380)$ & $0.79(222)$ & $0.89(380)$ \\
\hline PortaSCC color test & & 1.00 & $0.85(380)$ & $0.87(222)$ & $0.74(380)$ \\
\hline PortaSCC reader & & & 1.00 & $0.75(222)$ & $0.59(380)$ \\
\hline PortaSCC quick test & & & & 1.00 & $0.68(222)$ \\
\hline CMT & & & & & 1.00 \\
\hline \multicolumn{6}{|l|}{ Freshening } \\
\hline DeLaval SCC & 1.00 & $0.75(329)$ & $0.62(329)$ & $0.65(266)$ & $0.74(329)$ \\
\hline PortaSCC color test & & 1.00 & $0.81(329)$ & $0.83(266)$ & $0.74(329)$ \\
\hline PortaSCC reader & & & 1.00 & $0.71(266)$ & $0.63(329)$ \\
\hline PortaSCC quick test & & & & 1.00 & $0.74(266)$ \\
\hline CMT & & & & & 1.00 \\
\hline
\end{tabular}

${ }^{1}$ The $P$-value for all comparisons was $<0.001$.

${ }^{2}$ DeLaval cell counter: DeLaval International AB (Tumba, Sweden); PortaSCC tests: PortaCheck (Moorestown, NJ). 
was more strongly associated with SCC measured by the reference method in dry cows $\left(\mathrm{r}_{\mathrm{s}}=0.89\right)$ but not in fresh cows $\left(\mathrm{r}_{\mathrm{s}}=0.74\right)$.

The median SCC measured at dry-off were 126,000 (n $=126), 348,500(\mathrm{n}=124), 682,500(\mathrm{n}=89), 1,330,500$ $(\mathrm{n}=24), 1,995,500(\mathrm{n}=8)$, and $3,945,000(\mathrm{n}=9)$ cells/mL in quarters with PortaSCC color test values of $\leq 100,000,250,000,500,000,750,000,1,500,000$, and $\geq 3,000,000$ cells $/ \mathrm{mL}$, respectively (Figure $1 \mathrm{~A}$ ). For
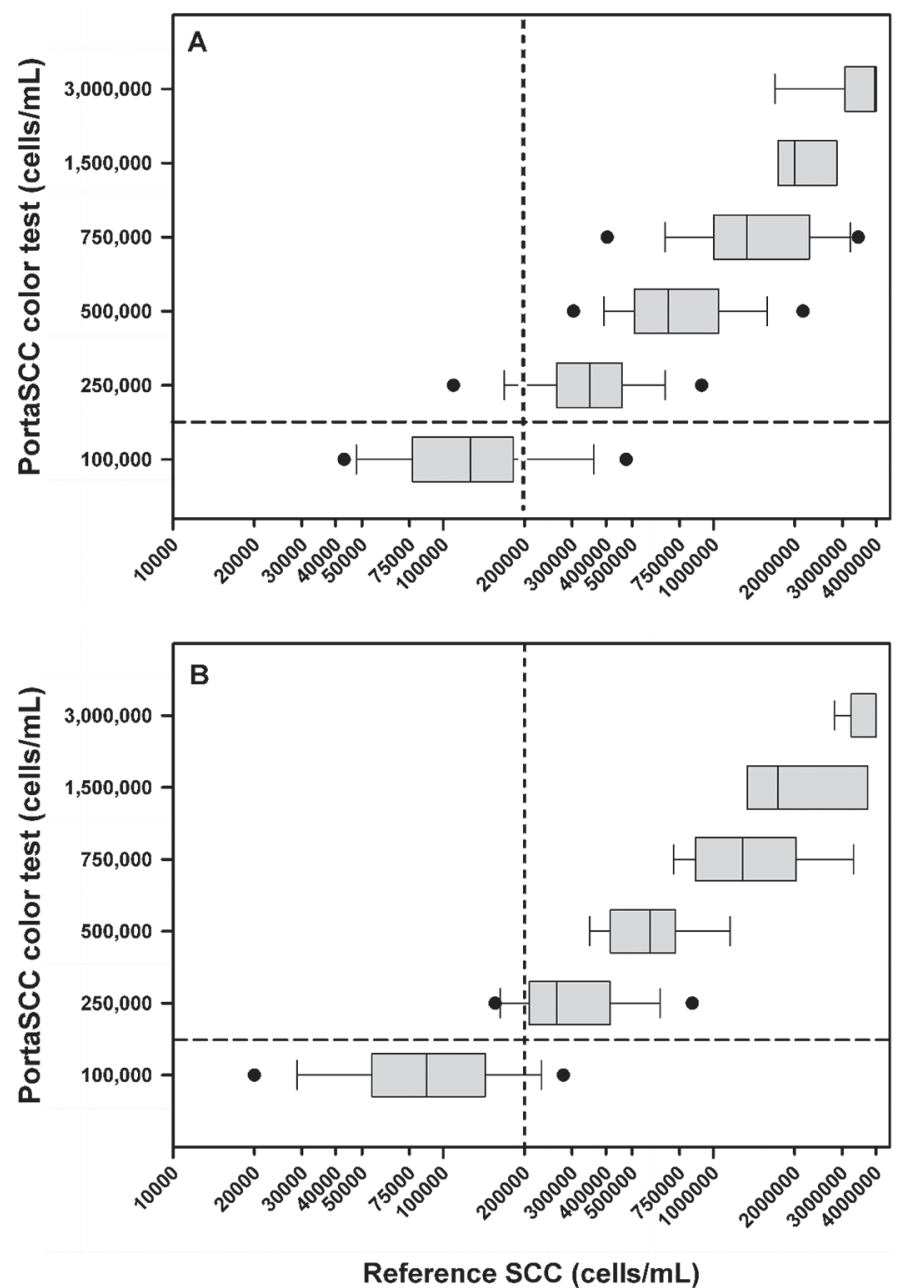

Figure 1. Box and whisker plots of the association between the PortaSCC (PortaCheck, Moorestown, NJ) color test category (6 levels) and SCC measured by the reference method in (A) 380 quarter milk samples obtained from 96 dairy cows at dry-off, and (B) 329 quarter milk samples obtained from 83 dairy cows at freshening. The shaded box represents the first and third quartiles, the vertical line in the shaded box represents the median value, the whiskers represent the 10th and 90th percentiles, and filled circles represent data points outside this percentile range. Vertical dashed lines indicate the SCC cut-point for diagnosing subclinical mastitis $(>200,000$ cells $/ \mathrm{mL})$, and horizontal dashed lines indicate the optimal cut-point for the test in diagnosing subclinical mastitis. comparison, the median SCC measured at freshening were $87,000(\mathrm{n}=233), 262,500(\mathrm{n}=48), 583,000$ $(\mathrm{n}=15), 1,284,000(\mathrm{n}=15), 1,731,000(\mathrm{n}=7)$, and $4,000,000(\mathrm{n}=11)$ cells $/ \mathrm{mL}$ in quarters with PortaSCC color test values of $\leq 100,000,250,000,500,000,750,000$, $1,500,000$, and $\geq 3,000,000$ cells $/ \mathrm{mL}$, respectively (Figure 1B).

The PortaSCC reader provided a "LO" reading on $42 \%(160 / 380)$ of the quarter samples obtained at dry-off, and these 160 samples were not included in the methods comparison analysis (Figure 2). PassingBablok regression of the comparison between measured $\log _{10}$ (SCC) using the PortaSCC reader and the reference method at dry-off had a proportional bias of 0.97 (95\% CI: 0.84 to 1.09 , which included 1) and a constant bias of 0.01 (95\% CI: -0.69 to 0.72 , which was less than 1) $\left[\log _{10}(1)=0\right.$; Figure $\left.2 \mathrm{~A}\right]$. The accompanying BlandAltman plot indicated that the PortaSCC reader read $\log _{10}$ (SCC) $3.4 \%$ lower than the reference method $(P<$ 0.001 compared with 0) and $95 \%$ limits of agreement from -16.0 to $9.1 \%$ (Figure $2 \mathrm{~B}$ ). The calculated range for the $95 \%$ limits of agreement of $25.1 \%$ approximated the $25 \%$ range regarded a priori as being acceptable for $\log _{10}(\mathrm{SCC})$.

The PortaSCC reader provided a "LO" reading in $24 \%$ $(78 / 329)$ of the quarter samples obtained at freshening, and these 78 samples were not included in the methods comparison analysis (Figure 3). Passing-Bablok regression of the comparison between measured $\log _{10}(\mathrm{SCC})$ using the PortaSCC reader and the reference method at freshening had a proportional bias of 1.05 (95\% CI: 0.91 to 1.22 , which included 1) and a constant bias of -0.38 (95\% CI: -1.49 to 0.41 , which was less than 1) $\left[\log _{10}(1)=0\right.$; Figure $\left.3 \mathrm{~A}\right]$. The accompanying BlandAltman plot indicated that the PortaSCC reader read $\log _{10}$ (SCC) $2.9 \%$ lower than the reference method $(P<$ 0.001 compared with 0) and $95 \%$ limits of agreement from -14.4 to $8.6 \%$ (Figure 3B). The calculated range for the $95 \%$ limits of agreement of $23.0 \%$ was within the $25 \%$ range regarded a priori as being acceptable for $\log _{10}(\mathrm{SCC})$.

The median SCC measured at dry-off was 158,500 (n $=78), 403,500(\mathrm{n}=78), 831,500(\mathrm{n}=38), 1,330,500$ $(\mathrm{n}=16), 3,182,000(\mathrm{n}=6)$, and $3,946,500(\mathrm{n}=6)$ cells/mL in quarters with PortaSCC quick test values of $\leq 100,000,250,000,500,000,750,000,1,500,000$, and $\geq 3,000,000$ cells $/ \mathrm{mL}$, respectively (Figure $4 \mathrm{~A}$ ). For comparison, the median SCC measured at freshening was $95,500(\mathrm{n}=212), 439,000(\mathrm{n}=25), 719,000(\mathrm{n}=$ 11), $1,517,000(\mathrm{n}=9), 2,876,000(\mathrm{n}=5)$, and $4,000,000$ $(\mathrm{n}=4)$ cells $/ \mathrm{mL}$ in quarters with PortaSCC quick test values of $\leq 100,000,250,000,500,000,750,000,1,500,000$, and $\geq 3,000,000$ cells $/ \mathrm{mL}$, respectively (Figure $4 \mathrm{~B}$ ). 
Agreement charts are provided for the PortaSCC color and quick tests at dry-off and freshening (Figure 5). At dry-off, the PortaSCC color test exhibited good agreement $(\kappa=0.68 ; 95 \%$ CI: $0.63-0.73)$ with
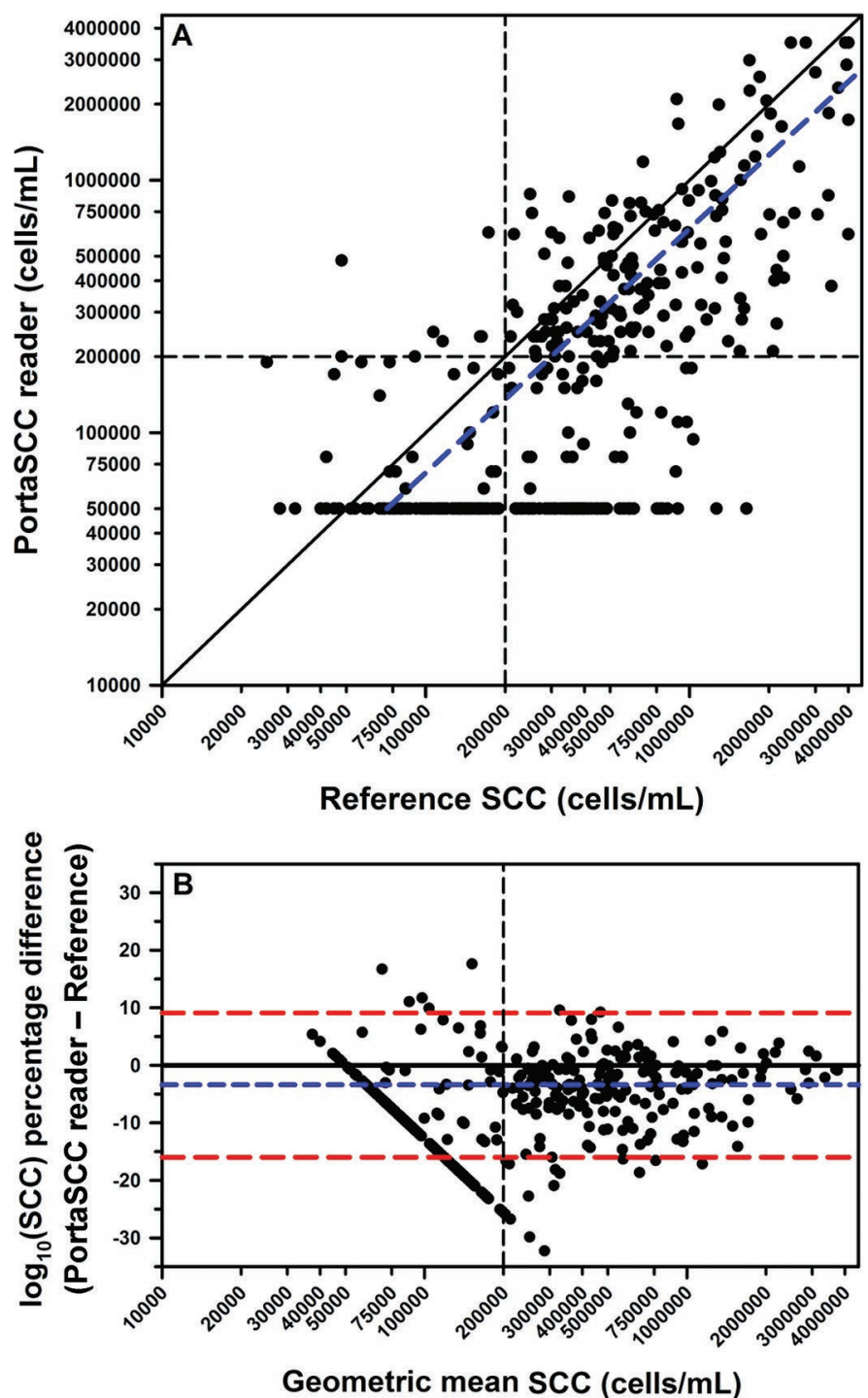

Figure 2. (A) Scatterplot of the relationship between the SCC measured by PortaSCC (PortaCheck, Moorestown, NJ) reader and the reference method in 380 quarter milk samples obtained from 96 dairy cows at dry-off. The diagonal solid line is the line of identity, and the dashed blue line is the line of best fit from Passing-Bablok regression using only PortaSCC reader values $>50,000$ cells $/ \mathrm{mL}(\mathrm{n}=225$ quarters). The horizontal dashed line is the optimal cut-point $(\geq 200,000$ cells $/ \mathrm{mL}$ ) for diagnosing subclinical mastitis that was identified using logistic regression. (B) Bland-Altman plot of the percentage difference between $\log _{10}(\mathrm{SCC})$ measured by the PortaSCC reader and reference method against the geometric mean value for SCC at dry-off using only the PortaSCC reader values $>50,000$ cells $/ \mathrm{mL}(\mathrm{n}=225$ quarters). The horizontal short dashed line is the mean bias $(-3.4 \%)$ and the horizontal long dashed lines reflect the $95 \%$ limits of agreement $(-16.0$ to $9.1 \%)$, which is equivalent to the range of differences containing $95 \%$ of future measurements. The vertical dashed lines indicate the cut-point for diagnosing subclinical mastitis $(>200,000$ cells $/ \mathrm{mL})$. the reference method for SCC, whereas the PortaSCC quick test had moderate agreement $(\kappa=0.58 ; 95 \% \mathrm{CI}$ : 0.50-0.66), with the PortaSCC reader having the lowest value for agreement $(\kappa=0.46 ; 95 \%$ CI: $0.40-0.53)$. The
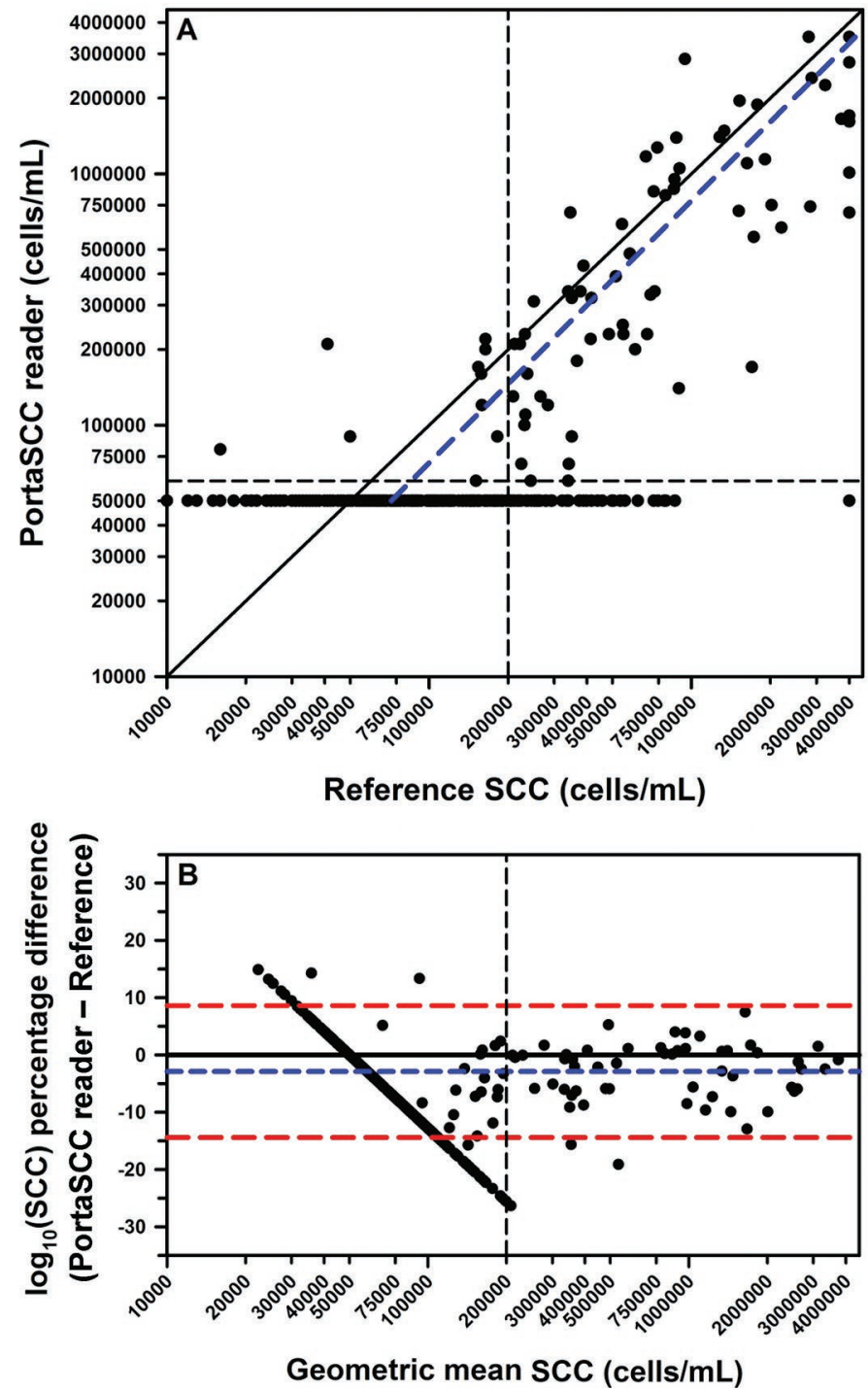

Figure 3. (A) Scatterplot of the relationship between the SCC measured by PortaSCC (PortaCheck, Moorestown, NJ) reader and the reference method in 329 quarter milk samples obtained from 83 dairy cows at freshening. The diagonal solid line is the line of identity, and the dashed blue line is the line of best fit from Passing-Bablok regression using only the PortaSCC reader values $>50,000$ cells $/ \mathrm{mL}(\mathrm{n}=78$ quarters). The horizontal dashed line is the optimal cut-point $(\geq 60,000$ cells $/ \mathrm{mL}$ ) for diagnosing subclinical mastitis that was identified using logistic regression. (B) Bland-Altman plot of the percentage difference between $\log _{10}(\mathrm{SCC})$ measured by the PortaSCC reader and reference method against the geometric mean value for SCC at freshening using only PortaSCC reader values $>50,000$ cells $/ \mathrm{mL}$ ( $\mathrm{n}=78$ quarters). The horizontal short dashed line is the mean bias $(-2.9 \%)$ and the horizontal long dashed lines reflect the $95 \%$ limits of agreement ( -14.4 to $8.6 \%$ ), which is equivalent to the range of differences containing $95 \%$ of future measurements. The vertical dashed lines indicate the cut-point for diagnosing subclinical mastitis $(>200,000$ cells/mL). 

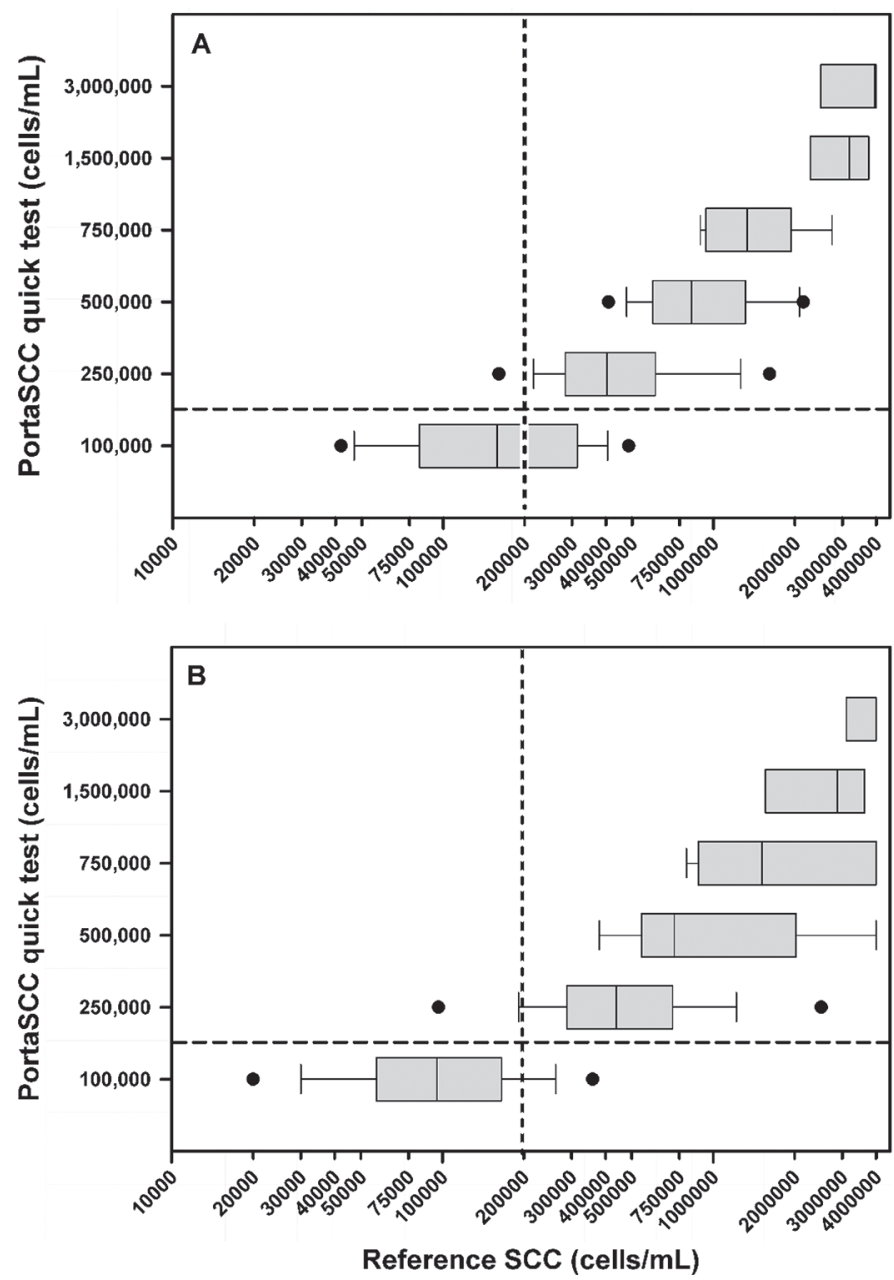

Figure 4. Box and whisker plots of the association between the PortaSCC (PortaCheck, Moorestown, NJ) quick test category (6 levels) and the SCC measured by the reference method for (A) 222 quarter milk samples obtained from 56 dairy cows at dry-off ( 2 cows had one blind quarter), and (B) 266 quarter milk samples obtained from 67 cows at freshening ( 2 cows had one blind quarter). The shaded box represents the first and third quartile, the vertical line in the shaded box represents the median value, the whiskers represent the 10th and 90th percentiles, and filled circles represent data points outside this percentile range. The vertical dashed lines indicate the SCC cut-point for diagnosing subclinical mastitis ( $>200,000$ cells $/ \mathrm{mL}$ ). The horizontal dashed lines indicate the optimal cut-point for the test in diagnosing subclinical mastitis.

PortaSCC color test and quick test exhibited excellent agreement $(\kappa=0.84 ; 95 \% \mathrm{CI}: 0.78-0.89$; agreement chart not shown). At freshening, the PortaSCC color test exhibited moderate agreement $(\kappa=0.57 ; 95 \%$ CI: 0.50-0.65) with the reference method for SCC, as did the PortaSCC quick test $(\kappa=0.40 ; 95 \%$ CI: $0.32-0.49)$, with the PortaSCC reader having the lowest value for agreement ( $\kappa=0.39 ; 95 \%$ CI: $0.31-0.46)$. The PortaS$\mathrm{CC}$ color test and quick test had good agreement $(\kappa=$ 0.79; 95\% CI: 0.72-0.87; agreement chart not shown).

\section{Logistic Regression Analysis for Diagnosis of SCM}

Logistic regression analysis indicated that the PortaSCC color test provided the best method for diagnosing SCM at dry-off and freshening compared with the PortaSCC reader and PortaSCC quick test, based on AUC, Se, and $\kappa$ (Table 3, Figures 1 to 4). The optimal cut-points identified by logistic regression for diagnosing SCM at dry-off, defined as SCC $>200,000$ cells $/ \mathrm{mL}$, were $\geq 250,000$ for PortaSCC color and quick tests and $\geq 200,000$ for the PortaSCC reader (Table 3, Figures $1 \mathrm{~A}, 2$, and $4 \mathrm{~A})$. For comparison, the optimal cut-points for diagnosing SCM at freshening were $\geq 250,000$ for PortaSCC color and quick tests and $\geq 60,000$ for the PortaSCC reader (Table 3, Figures 1B, 3, and 4B).

Logistic regression analysis indicated that the AUC for the PortaSCC color test at dry-off was greater $(P<$ 0.001) than that for the PortaSCC reader but similar to that for the PortaSCC quick test $(P=0.29$; Table $3)$; the AUC for the latter 2 tests were different $(P<$ 0.001). At freshening, logistic regression analysis indicated that the AUC for the PortaSCC color test was greater $(P<0.001)$ than that for the PortaSCC reader and the PortaSCC quick test; the AUC for the latter 2 tests were similar $(P=0.55)$.

The Se, Sp, +LR, and $\kappa$ values at dry-off and freshening, based on the optimal cut-points, are presented in Table 3 . The $\kappa$ values that were calculated using the optimal cut-points for SCM indicated good agreement between the reference method and the PortaSCC color test $(\kappa=0.71)$ or PortaSCC quick test $(\kappa=0.58)$ at dry-off, and between the reference method and the PortaSCC color test $(\kappa=0.72)$ or PortaSCC quick test $(\kappa=0.62)$ at freshening. The agreement between the reference method and the PortaSCC reader was only moderate at dry-off $(\kappa=0.43)$ and at freshening $(\kappa=$ $0.58)$.

\section{Logistic Regression Analysis for Diagnosis of IMI}

Values for the optimal cut-point, AUC, Se, Sp, +LR, and $\kappa$ for diagnosing IMI at dry-off and freshening determined using logistic regression analysis are presented in Table 4. The optimal cut-points identified by logistic regression for diagnosing IMI at dry-off, defined as bacterial count $\geq 100 \mathrm{cfu} / \mathrm{mL}$, were $\geq 500,000$ for PortaSCC color and quick tests and $\geq 80,000$ for the PortaSCC reader (Table 4). For comparison, the optimal cut-points for diagnosing IMI at freshening were $\geq 250,000$ for PortaSCC color test, $\geq 500,000$ for PortaSCC quick test, and $\geq 60,000$ for the PortaSCC reader (Table 4 ).

Logistic regression analysis indicated that the AUC for the PortaSCC color test at dry-off was similar to 
Agreement of DeLaval SCC and PortaSCC color test

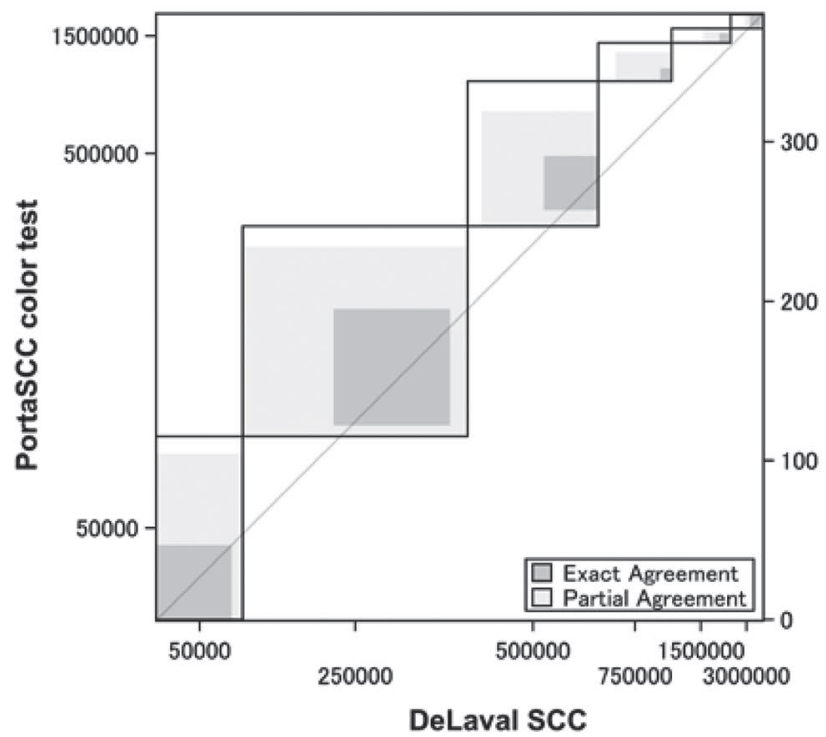

Agreement of DeLaval SCC and PortaSCC color test

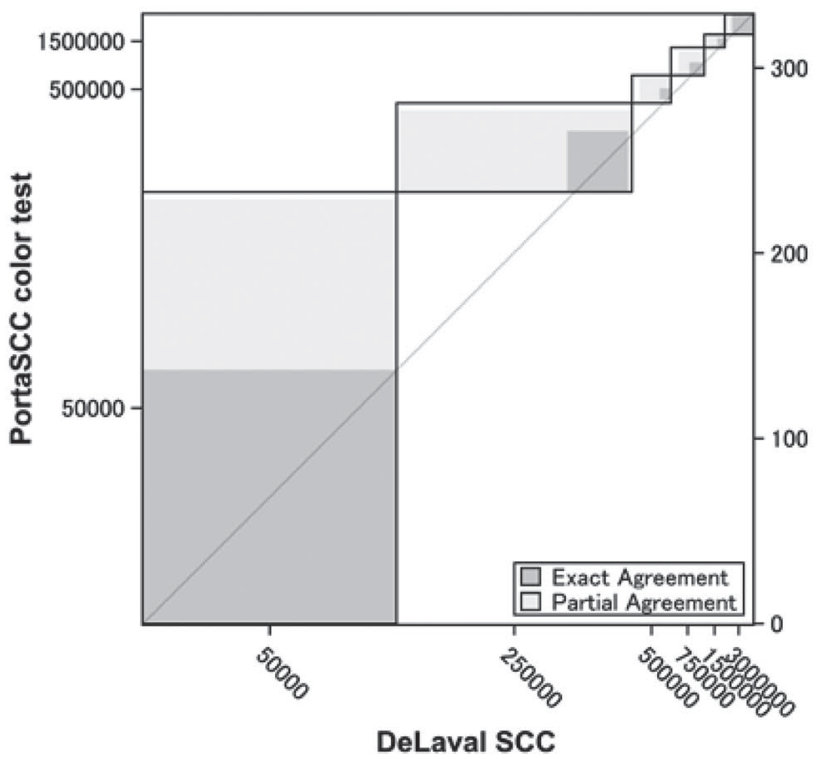

Agreement of DeLaval SCC and PortaSCC quick test

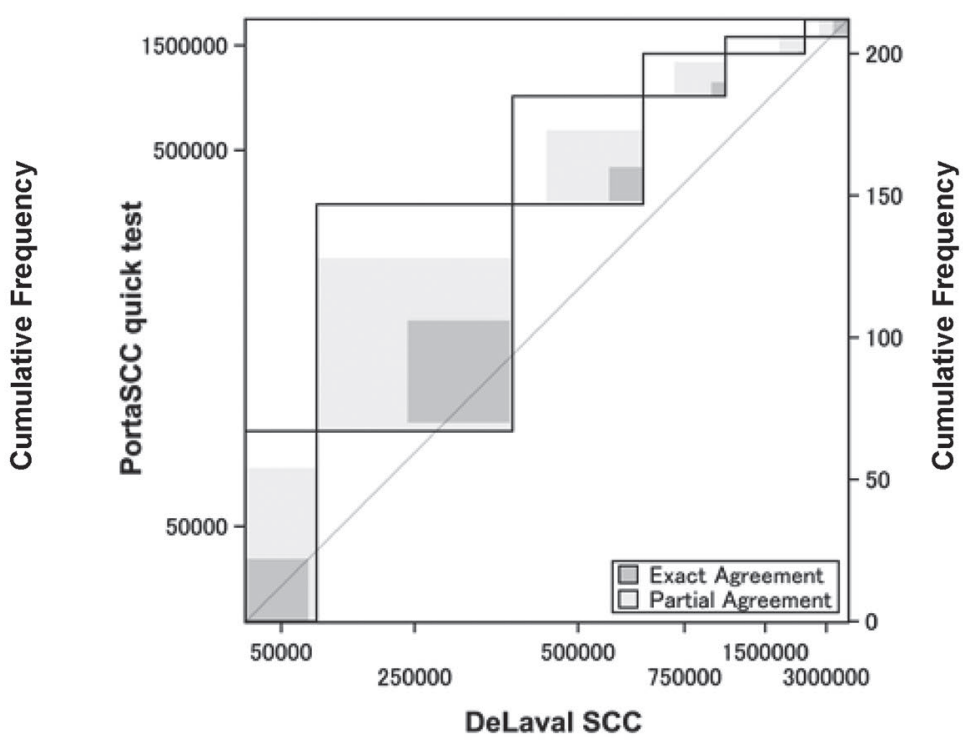

Agreement of DeLaval SCC and PortaSCC quick test

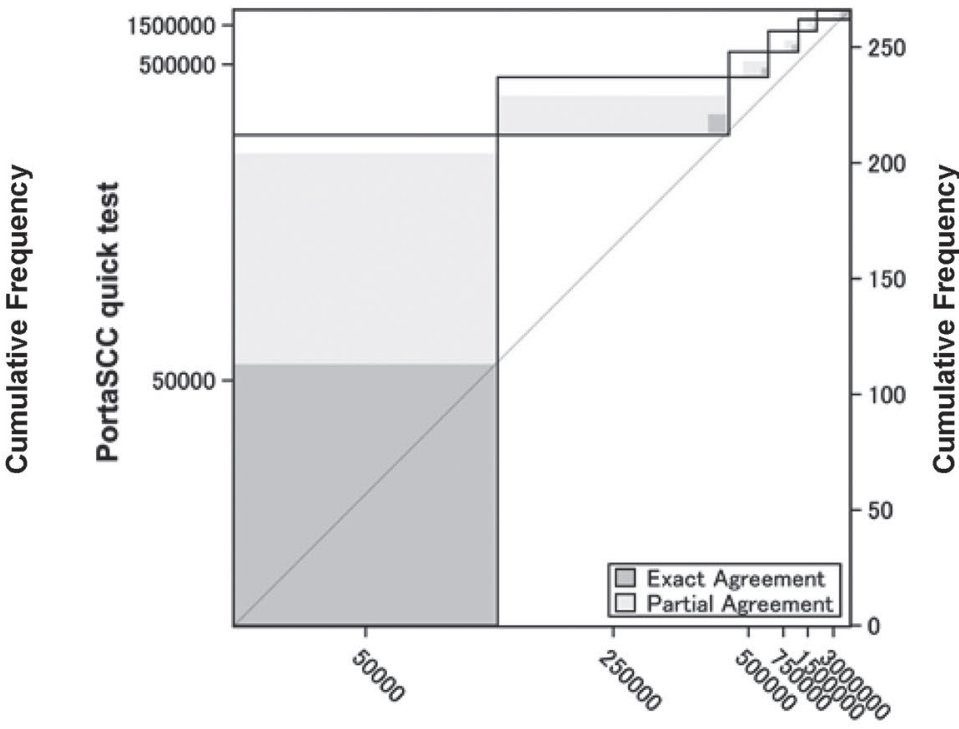

DeLaval SCC

Figure 5. Agreement charts for comparing SCC for the PortaSCC (PortaCheck, Moorestown, NJ) color test (top left, $\mathrm{n}=380 \mathrm{quarters)}$ and the PortaSCC quick test (top right, $\mathrm{n}=222$ quarters) at dry-off, and for the PortaSCC color test (bottom left, $\mathrm{n}=329$ quarters) and the PortaSCC quick test (bottom right, $\mathrm{n}=280$ quarters) at freshening. The darker squares represent exact agreement for each category, whereas the lighter squares represent partial agreement for the category (defined as the adjacent off-diagonal table cells, where the row and column values are within 1 level of exact agreement). The unshaded area within each square represents no agreement. DeLaval cell counter: DeLaval International AB (Tumba, Sweden).

that of the PortaSCC quick test $(P=0.82)$ but greater $(P<0.001)$ than that for the PortaSCC reader. The AUC for the PortaSCC quick test was similar to that for the PortaSCC reader $(P=0.062)$. At freshening, logistic regression analysis indicated that the AUC for the PortaSCC color test was greater $(P=0.018)$ than that for the PortaSCC reader and greater $(P=0.0033)$ than that for the PortaSCC quick test. The AUC for the PortaSCC reader and PortaSCC quick test were similar $(P=0.55)$.

The $\kappa$ values calculated using the optimal cut-points for IMI indicated moderate agreement between the 
Table 3. Summary of the results of logistic regression analysis of the ability of 3 PortaSCC tests (PortaCheck, Moorestown, NJ) and the California Mastitis Test (CMT) to predict subclinical mastitis, as defined by an SCC >200,00 cells/mL, in quarter milk samples obtained from 96 dairy cows at dry-off and 83 dairy cows at freshening ${ }^{1}$

\begin{tabular}{|c|c|c|c|c|c|c|c|}
\hline Variable & $\mathrm{n}$ & $\begin{array}{l}\text { Optimal } \\
\text { cut-point }\end{array}$ & AUC & Sensitivity & Specificity & $+\mathrm{LR}$ & $\kappa$ \\
\hline \multicolumn{8}{|l|}{ Dry-off } \\
\hline PortaSCC color test & 380 & $\geq 250,000$ & $\begin{array}{l}0.90^{\mathrm{a}} \\
(0.87-0.93)\end{array}$ & $\begin{array}{l}0.91 \\
(0.87-0.94)\end{array}$ & $\begin{array}{l}0.81 \\
(0.72-0.87)\end{array}$ & $\begin{array}{l}4.7 \\
(3.2-6.8)\end{array}$ & $\begin{array}{l}0.71 \\
(0.63-0.79)\end{array}$ \\
\hline PortaSCC reader & 380 & $\geq 200,000$ & $\begin{array}{l}0.80^{\mathrm{b}} \\
(0.76-0.84)\end{array}$ & $\begin{array}{l}0.63 \\
(0.57-0.69)\end{array}$ & $\begin{array}{l}0.89 \\
(0.82-0.94)\end{array}$ & $\begin{array}{l}6.0 \\
(3.5-10.3)\end{array}$ & $\begin{array}{l}0.43 \\
(0.35-0.51)\end{array}$ \\
\hline PortaSCC quick test & 222 & $\geq 250,000$ & $\begin{array}{l}0.86^{\mathrm{a}} \\
(0.82-0.91)\end{array}$ & $\begin{array}{l}0.83 \\
(0.77-0.89)\end{array}$ & $\begin{array}{l}0.82 \\
(0.68-0.91)\end{array}$ & $\begin{array}{l}4.5 \\
(2.5-8.2)\end{array}$ & $\begin{array}{l}0.58 \\
(0.46-0.70)\end{array}$ \\
\hline \multicolumn{8}{|l|}{ Freshening } \\
\hline PortaSCC color test & 329 & $\geq 250,000$ & $\begin{array}{l}0.86^{\mathrm{a}} \\
(0.82-0.90)\end{array}$ & $\begin{array}{l}0.74 \\
(0.65-0.82)\end{array}$ & $\begin{array}{l}0.95 \\
(0.92-0.98)\end{array}$ & $\begin{array}{l}15.8 \\
(8.5-29.2)\end{array}$ & $\begin{array}{l}0.72 \\
(0.54-0.80)\end{array}$ \\
\hline PortaSCC reader & 329 & $\geq 60,000$ & $\begin{array}{l}0.78^{\mathrm{b}} \\
(0.73-0.83)\end{array}$ & $\begin{array}{l}0.59 \\
(0.49-0.68)\end{array}$ & $\begin{array}{l}0.95 \\
(0.92-0.98)\end{array}$ & $\begin{array}{l}12.5 \\
(6.7-23.3)\end{array}$ & $\begin{array}{l}0.58 \\
(0.49-0.68)\end{array}$ \\
\hline PortaSCC quick test & 266 & $\geq 250,000$ & $\begin{array}{l}0.78^{\mathrm{b}} \\
(0.73-0.83)\end{array}$ & $\begin{array}{l}0.57 \\
(0.46-0.67)\end{array}$ & $\begin{array}{l}0.99 \\
(0.96-1.00)\end{array}$ & $\begin{array}{l}51.0 \\
(12.5-200.6)\end{array}$ & $\begin{array}{l}0.62 \\
(0.52-0.72)\end{array}$ \\
\hline
\end{tabular}

${ }^{\mathrm{a}-\mathrm{c}}$ Tests with different superscripts for the AUC at dry-off or freshening are significantly different $(P<0.001)$.

${ }^{1} \mathrm{n}=$ number of quarters used in the analysis; optimal cut-point is in cells/mL (PortaSCC tests) or CMT score; AUC $=$ area under the receiver operating characteristic curve; $+\mathrm{LR}=$ positive likelihood ratio at the optimal cut-point; $\kappa=$ kappa coefficient (a measure of agreement between the test and reference method using the optimal cut-point identified during logistic regression). The $95 \%$ confidence interval for AUC, sensitivity, and specificity is given in parentheses.

culture result and PortaSCC quick test at dry-off $(\kappa$ $=0.40)$ and at freshening $(\kappa=0.46)$. Fair agreement was found between the culture result and the PortaSCC color test at dry-off $(\kappa=0.34)$ and freshening $(\kappa=$ $0.38)$, and between the culture result and the PortaSCC reader $(\kappa=0.34)$ at freshening.

Table 4. Summary of the results of logistic regression analysis of the ability of 3 PortaSCC tests (PortaCheck, Moorestown, NJ) and the California Mastitis Test (CMT) to predict IMI, as defined by bacteria count $\geq 100 \mathrm{cfu} / \mathrm{mL}$, in quarter milk samples obtained from 96 dairy cows at dry-off and 83 dairy cows at freshening

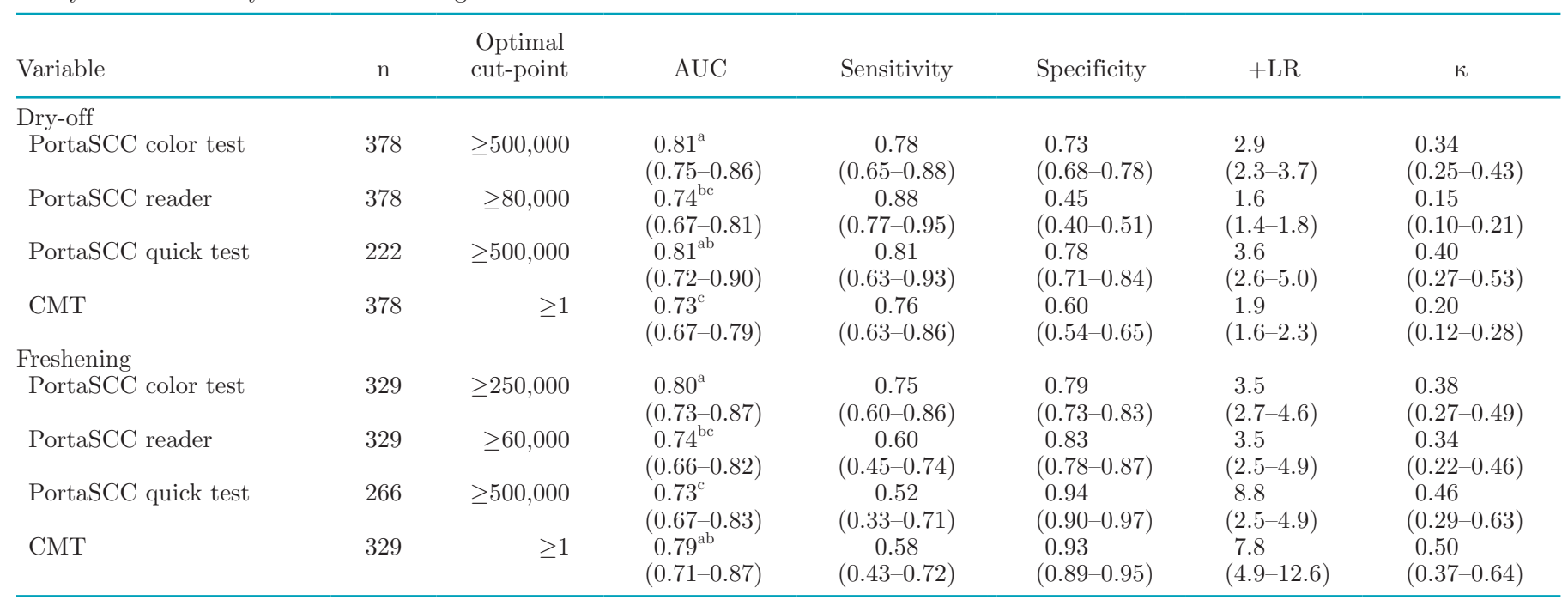

\footnotetext{
${ }^{a-c}$ Tests with different superscripts for the AUC at dry-off or freshening are significantly different $(P<0.001)$.
}

${ }^{1} \mathrm{n}=$ number of quarters used in the analysis; optimal cut-point is in cells/mL (PortaSCC tests) or CMT score; AUC $=$ area under the receiver operating characteristic curve; $+\mathrm{LR}=$ positive likelihood ratio at the optimal cut-point; $\kappa=$ kappa coefficient (a measure of agreement between the test and reference method using the optimal cut-point identified during logistic regression). The $95 \%$ confidence interval for AUC, sensitivity, and specificity is given in parentheses. 


\section{Comparison with the CMT}

The AUC for diagnosing SCM at dry-off (Table 3) was greater for the CMT than for the PortaSCC color test $(P<0.001)$, PortaSCC quick test $(P<0.001)$, or PortaSCC reader $(P<0.001)$. The AUC for diagnosing SCM at freshening for the CMT was similar to that for the PortaSCC color test $(P=0.37)$ but greater than that for the PortaSCC quick test $(P<0.001)$ or PortaSCC reader $(P<0.001)$.

The CMT had a higher Se and $\kappa$ value for diagnosing SCM than all 3 PortaSCC tests at dry-off and freshening (Table 3). There was excellent agreement between the reference method and CMT at dry-off $(\kappa=0.81)$ and good agreement between the reference method and CMT at freshening $(\kappa=0.76)$.

The AUC for diagnosing IMI at dry-off was lower for the CMT (Table 4) than for the PortaSCC color test $(P=0.0047)$ or the PortaSCC quick test $(P=$ $0.0015)$, whereas there was no difference at dry-off in the AUC between the CMT and PortaSCC reader $(P$ $=0.89$ ). The AUC for diagnosing IMI at freshening for the CMT test was similar to that for the PortaSCC color test $(P=0.54)$ and the PortaSCC reader $(P=$ 0.12 ) but greater than that for the PortaSCC quick test $(P=0.037)$. The CMT had a lower Se for diagnosing IMI than all 3 PortaSCC tests at dry-off and freshening (Table 4 ) but the highest $\kappa$ value at freshening.

\section{Effect of Sample Temperature}

We detected no effect of temperature on the PortaSCC color test $(P=0.90)$, the PortaSCC color test $(P=0.62)$, or the PortaSCC reader value $(P=0.072)$. Least squares means SCC values were 217,520 cells/ $\mathrm{mL}$ at $4^{\circ} \mathrm{C}, 262,422$ cells $/ \mathrm{mL}$ at room temperature, and 242,270 cells $/ \mathrm{mL}$ at $37^{\circ} \mathrm{C}$.

\section{DISCUSSION}

This study evaluated the performance of 3 PortaSCC tests in dairy cattle in one herd and compared their clinical utility to the CMT as cow-side tests at dryoff and at freshening for diagnosing SCM, defined as SCC $>200,000 / \mathrm{mL}$, and IMI, defined as $\geq 100 \mathrm{cfu} / \mathrm{mL}$. The first major finding of this study was that of the 3 PortaSCC tests, the PortaSCC color test was the best for diagnosing SCM at dry-off and freshening at an optimal cut-point of $\geq 250,000$ cells $/ \mathrm{mL}$. The second major finding was that the PortaSCC reader did not improve the accuracy of the PortaSCC color test at dry-off or freshening. The third major finding was that the CMT was more accurate than the PortaSCC color test for diagnosing SCM at dry-off and as accurate for diagnosing SCM at freshening. The fourth major finding was that the PortaSCC quick test was the best-performing PortaSCC test for diagnosing IMI at dry-off, and the PortaSCC color test was the best-performing PortaSCC test for diagnosing IMI at freshening. For comparison, the CMT was inferior to the PortaSCC quick test for diagnosing IMI at dry-off but equivalent to the PortaSCC color test at freshening.

A long-standing goal for our laboratory has been to find a rapid, accurate on-farm or cow-side test for identifying quarters with SCM and IMI. We considered that the Se and $\mathrm{Sp}$ of the tests under evaluation were equally important. On this basis, $\mathrm{AUC},+\mathrm{LR}$, and $\kappa$ are useful indices for the overall performance of a clinical test. Ideally, such a test should have an AUC $>0.80$ (preferably $>0.90$ ), Se and Sp as high as possible, $+\mathrm{LR}$ $>10$, and $\kappa>0.6$. On this basis, the PortaSCC color test, the PortaSCC quick test, and the CMT could generally be described as good diagnostic tests when applied to the study population. The CMT can be performed cow-side within 2 min at an estimated cost of US $\$ 0.15 /$ test. In comparison, the PortaSCC color test is most easily performed in a dedicated room on the farm and required $45 \mathrm{~min}$ to obtain a result at an estimated cost of $\$ 0.90 /$ test. The PortaSCC reader costs an additional $\$ 230$ for the analyzer and was less accurate than the PortaSCC color test; consequently, our results suggest that the PortaSCC reader does not add value to the diagnostic testing strategy compared with the PortaSCC color test alone. The PortaSCC quick test is most easily performed in a dedicated room on the farm but required only 5 min to obtain results at an estimated cost of $\$ 1.25 /$ test.

The superior performance of PortaSCC tests for diagnosing SCM at dry-off compared with freshening may be related to a different milk color or viscosity at dry-off that affects the dye intensity or absorption of the milk sample into the test strip pad. Alternatively, the difference may simply reflect differences in the median SCC values at dry-off $(364,000$ cells $/ \mathrm{mL})$ and freshening $(130,000$ cells $/ \mathrm{mL})$ because the PortaSCC tests are suspected to have a narrow zone for detecting borderline SCC values (Salvador et al., 2014). The difference in performance between the PortaSCC color test and PortaSCC reader in predicting quarters with SCM was unexpected. The relatively low performance of the PortaSCC reader in fresh cow milk compared with that in milk obtained from cows at dry-off in this study may be due to the effect of different milk composition such as fat and protein content on the performance of the reader. Because the PortaSCC color and quick tests are evaluated through subjective colorimetry, changes in color may be inconsistently interpreted by different observers. Consequently, the PortaSCC color and quick 
tests should be viewed as subjective tests, similar to the CMT.

The PortaSCC tests are among several commercially available esterase tests to detect leukocytes in a variety of body fluids. For example, the Multistix urine test strip pad (Siemens Healthcare Diagnostics Inc., Tarrytown, NY) contains a detergent and 3-hydroxy-5-phenyl-pyrole esterified with an amino acid that is used as a substrate for esterase (Mendler et al., 2010), thereby releasing a pyrrole compound that reacts with a diazonium salt to yield a violet/purple azo dye. The intensity of the violet color is correlated with the leukocyte count in urine (Kutter et al., 1987). The PeriScreen test strip (Serim Research Corp., Elkhart, IN) is designed to provide a semiquantitative indication of leukocyte concentration in peritoneal dialysate effluent for the early identification of peritonitis. The reaction on the test strip pad is based on esterase catalyzing the hydrolysis of an indoxyl ester compound to indoxyl that reacts with a diazonium salt to produce a violet/purple color; as with the Multistix strip, the intensity of the color is correlated with the leukocyte count (Mendler et al., 2010). We recently investigated the clinical utility of the Multistix and PeriScreen strips in diagnosing SCM in lactating dairy cattle (Kandeel et al., 2017). The tests are available at an estimated cost of $\$ 0.36$ / test and $\$ 4.00 /$ test, respectively. In contrast to the findings reported here regarding the PortaSCC tests, we concluded that the Multistix and PeriScreen strips were not clinically useful cow-side tests for diagnosing SCM (Kandeel et al., 2017).

We defined IMI as the isolation of at least $100 \mathrm{cfu} /$ $\mathrm{mL}$ of milk, which is equivalent to the isolation of a single colony from $0.01 \mathrm{~mL}$ of milk (Dohoo et al., 2011) to identify infected cows with low levels of pathogen shedding. We built our diagnosis on a single milk sample from each gland. The inability to isolate bacteria from quarter milk samples with elevated SCC in our study may be due to bacteria not being the cause of udder inflammation of these glands (unspecific mastitis), a low concentration of pathogenic microorganisms in milk, intermittent shedding of pathogens into the glandular secretion, intracellular location of pathogens, the presence of some growth inhibitors in milk, or the spontaneous elimination of infection from the udder (Constable et al., 2016). Failure may be also attributed to a delay in healing after elimination of the infection due to continued infiltration of leukocytes into the gland. The SCC is influenced by breed, age, stage of lactation, milk production level, stress, season (Harmon, 1994; Schepers et al., 1997), milk fraction (Sarikaya and Bruckmaier, 2006), and time of day (Olde Riekerink et al., 2007). Nevertheless, the presence of a pathogen in the udder is considered the main factor responsible for an increase in milk SCC (Harmon, 1994; de Haas et al., 2002).

The PortaSCC color and quick tests performed better overall than the CMT in diagnosing IMI at dry-off and were similar in performance to the CMT at freshening, based on higher or similar values for AUC, Se, and $\kappa$. This finding was unexpected based on the assumption that milk esterase activity is correlated with milk leukocyte count, as IMI is usually accompanied by a marked increase in the milk leukocyte count (Kitchen, 1981; Pyörälä, 2003; Constable et al., 2016). However, the distribution of leukocytes differs between normal and mastitic milk (Nickerson, 1989); the proportions of neutrophils may reach 95\% in mastitic milk (Paape et al., 1979; Kehrli and Shuster, 1994), whereas macrophages and lymphocytes are the predominant cells in uninfected quarters (Schwarz et al., 2011a,b; Pilla et al., 2012). The results of recent studies suggest that milk with SCC $<100,000$ cells/mL and an elevated proportion of neutrophils indicates a local inflammatory reaction triggered by pathogens (Schwarz et al., 2011a,b; Pilla et al., 2012, 2013). A stronger correlation may therefore exist between an elevated neutrophil count, a main source of esterase activity in milk, and the presence of IMI, compared with a correlation between SCC and IMI. In addition, because esterase activity in plasma is typically 1,000 to 2,000 times its activity in milk (Marquardt and Forster, 1965), some of the esterase activity in milk might be due to the movement of plasma components into the mammary gland as a result of increased the permeability of blood-milk barrier during bacterial infection (Marquardt et al., 1966). The possible source of esterase from neutrophils or plasma may explain the better performance of PortaSCC tests over the CMT at dry-off for identifying quarters with IMI.

This study sampled foremilk after removal of approximately $10 \mathrm{~mL}$ but before alveolar milk could mix with cisternal milk (Sarikaya and Bruckmaier, 2006). This sampling strategy was selected to minimize within-cow variability in SCC due to all samples being collected within $50 \mathrm{~s}$ of first touching the udder and teat. The sampling strategy was also selected to reflect sampling practices on dairies where foremilk samples are most commonly collected for determination of IMI (Djabri et al., 2002). Foremilk has higher SCC than cisternal and alveolar milk when total quarter milk SCC exceeds 350,000 cells/mL (Sarikaya and Bruckmaier, 2006), but not when foremilk SCC ranges from 50,000 to 300,000 cells/mL (Wellnitz et al., 2009). On this basis, we believe that the SCC cut-point of 200,000 cells $/ \mathrm{mL}$ used in this study to define SCM approximated that measured in other studies, in which milk samples most likely reflected an admixture of cisternal and alveolar 
milk (Schepers et al., 1997). It should be noted that the cut-point of 200,000 cells/mL is an operational threshold of practical value under field conditions; it does not represent a physiological cell concentration in milk that differentiates "healthy" from "unhealthy" quarters (Schukken et al., 2003).

The 3 PortaSCC tests, although clinically useful as measures of SCM and particularly IMI in quarter milk samples obtained at dry-off and freshening, were not sufficiently accurate to overcome the requirements of additional time and added cost to recommend them over the CMT as screening tests to identify cows with SCM or IMI. The CMT has the advantages of cowside application, rapid results, low cost, and acceptable Se and Sp. This study conducted in one herd failed to identify a persuasive reason for preferring the PortaSCC color test, PortaSCC reader, or PortaSCC quick test over the CMT. Additional studies conducted in different cattle populations are warranted to confirm the results of this study.

\section{ACKNOWLEDGMENTS}

This research was supported, in part, by the Cultural and Educational Bureau, Embassy of the Arab Republic of Egypt (Washington, DC). The authors did not receive funding support or product donation from PortaCheck Inc. (Moorestown, NJ).

\section{REFERENCES}

Balaji, S. N., R. Saravanan, A. Senthilkumar, and G. Srinivasan. 2016. Effect of subclinical mastitis on somatic cell count and milk profile changes in dairy cows. Int. J. Sci. Environ. Technol. 5:4427-4431.

Bangdiwala, S. I., and V. Shankar. 2013. The agreement chart. BMC Med. Res. Methodol. 13:97.

Barnum, D. A., and F. H. S. Newbould. 1961. The use of the California Mastitis Test for the detection of bovine mastitis. Can. Vet. J. 2:83-90.

Bhutto, A. L., R. D. Murray, and Z. Woldehiwet. 2012. California mastitis test scores as indicators of subclinical intra-mammary infections at the end of lactation in dairy cows. Res. Vet. Sci. 92:13-17.

Bilić-Zulle, L. 2011. Lessons in biostatistics. Comparison of methods: Passing and Bablok regression. Biochem. Med. (Zagreb) 21:49-52.

Booth, R. A., G. E. Morse, and J. M. Treece. 1965. Relationship of Aesterase activity, blood serum albumin, and leucocyte count during experimental exposure to Streptococcus agalactia (Cornell Strain 48). J. Dairy Sci. 48:822.

Breen, J. E., A. J. Bradley, and M. J. Green. 2009. Quarter and cow risk factors associated with a somatic cell count greater than 199,000 cells per milliliter in United Kingdom dairy cows. J. Dairy Sci. 92:3106-3115.

Constable, P. D., K. W. Hinchcliff, S. H. Done, and W. Gruenberg. 2016. Mastitis. Pages 2113-2208 in Veterinary Medicine: A Textbook of the Diseases of Cattle, Horses, Sheep, Pigs and Goats. Elsevier Health Sciences, Philadelphia, PA.

de Haas, Y., H. W. Barkema, and R. F. Veerkamp. 2002. The effect of pathogen-specific clinical mastitis on the lactation curve for somatic cell count. J. Dairy Sci. 85:1314-1323.

Dingwell, R. T., K. E. Leslie, Y. H. Schukken, J. M. Sargeant, and L. T. Leo. 2003. Evaluation of the California mastitis test to detect an intramammary infection with a major mastitis pathogen in early lactation dairy cows. Can. Vet. J. 44:413-415.

Djabri, B., N. Bareille, F. Beaudeau, and H. Seegers. 2002. Quarter milk somatic cell count in infected dairy cows: a meta-analysis. Vet. Res. 33:335-357.

Dohoo, I. R., J. Smith, S. Andersen, D. F. Kelton, and S. Godden. 2011. Diagnosing intramammary infections: Evaluation of definitions based on a single milk sample. J. Dairy Sci. 94:250-261.

Forster, T. L., M. W. Montgomery, and J. E. Montoure. 1961. Some factors influencing the activity of the A-, B-, and C- esterases of bovine milk. J. Dairy Sci. 44:1420.

Fosgate, G. T., I. M. Petzer, and J. Karzis. 2013. Sensitivity and specificity of a hand-held milk electrical conductivity meter compared to the California mastitis test for mastitis in dairy cattle. Vet. J. 196:98-102.

Godden, S. M., E. Royster, J. Timmerman, P. Rapnicki, and H. Green. 2017. Evaluation of an automated milk leukocyte differential test and the California Mastitis Test for detecting intramammary infection in early-and late-lactation quarters and cows. J. Dairy Sci. 100:6527-6544

Grimes, D. A., and K. F. Schulz. 2005. Refining clinical diagnosis with likelihood ratios. Lancet 365:1500-1505.

Hanuš, O., K. Sojková, K. Hanušová, E. Samková, M. Hronek, R. Hyšpler, J. Kopecký, and R. Jedelská. 2014. An experimental comparison of methods for somatic cell count determination in milk of various species of mammals. Acta Univ. Agric. Silvic. Mendel. Brun. 59:67-82.

Harmon, R. J. 1994. Physiology of mastitis and factors affecting somatic cell counts. J. Dairy Sci. 77:2103-2112.

Hosmer, D. W., and S. Lemeshow. 1989. Applied Logistic Regression. John Wiley \& Sons, New York, NY.

Iraguha, B., H. Hamudikuwanda, B. Mushonga, E. Kandiwa, and J. P. Mpatswenumugabo. 2017. Comparison of cow-side diagnostic tests for subclinical mastitis of dairy cows in Musanze district, Rwanda. J. S. Afr. Vet. Assoc. 88:e1-e6.

Kandeel, S. A., M. E. Ebied, F. K. Arnaout, E. M. Galila, A. A. Megahed, and P. D. Constable. 2017. Clinical utility of two leukocyte esterase reagent strips for the cow-side diagnosis of subclinical mastitis in lactating dairy cattle. Assiut Vet. J. 63:1-10.

Kandeel, S. A., A. A. Megahed, F. K. Arnaout, and P. D. Constable. 2018b. Evaluation and comparison of two on-farm tests for estimating somatic cell count in quarter milk samples from lactating dairy cattle. J. Vet. Intern. Med. 32:506-515.

Kandeel, S. A., D. E. Morin, C. D. Calloway, and P. D. Constable. 2018a. Association of California Mastitis Test Scores with intramammary infection status in lactating dairy cows admitted to a veterinary teaching hospital. J. Vet. Intern. Med. 32:497-505.

Kawai, K., T. Hayashi, Y. Kiku, T. Chiba, H. Nagahata, H. Higuchi, T. Obayashi, S. Itoh, K. Onda, S. Arai, R. Sato, and T. Oshida. 2013. Reliability in somatic cell count measurement of clinical mastitis milk using DeLaval cell counter. Anim. Sci. J. 84:805-807.

Kehrli, M. E., and D. E. Shuster. 1994. Factors affecting milk somatic cells and their role in health of the bovine mammary gland. J. Dairy Sci. 77:619-627.

Kitchen, B. J. 1981. Review of the progress of dairy science: Bovine mastitis: Milk compositional changes and related diagnostic tests. J. Dairy Res. 48:167-188.

Kutter, D., G. Figueiredo, and L. Klemmer. 1987. Chemical detection of leukocytes in urine by means of a new multiple test strip. J. Clin. Chem. Clin. Biochem. 25:91-94.

Landis, J. R., and G. G. Koch. 1977. The measurement of observer agreement for categorical data. Biometrics 33:159-174.

Luedecke, L. O.. T. L. Forster, and U. S. Ashworth. 1967. Relationship between California Mastitis Test reaction and leucocyte count, catalase activity, and A-esterase activity of milk from opposite quarters. J. Dairy Sci. 50:1592-1596.

Malinowski, E., S. Smulski, M. Gehrke, A. Kłossowska, A. Arczyńska, and M. Kaczmarowski. 2008. Effect of storage conditions and preservation with Bronopol on somatic cell count with the DeLaval cell counter in cow milk. Med. Weter. 64:1299-1303. 
Marquardt, R. R., and T. L. Forster. 1965. Titrimetric procedure for assay of milk arylesterase activity. J. Dairy Sci. 48:1602-1606.

Marquardt, R. R., T. L. Forster, G. R. Spencer, and G. H. Stabenfeldt. 1966. A-esterase activities of milk from cows with experimentally induced mastitis. J. Dairy Sci. 49:631-635.

Mendler, M. H., A. Agarwal, M. Trimzi, E. Madrigal, M. Tsushima, E. Joo, M. Santiago, E. Flores, G. David, A. Workman, and B. Runyon. 2010. A new highly sensitive point of care screen for spontaneous bacterial peritonitis using the leukocyte esterase method. J. Hepatol. 53:477-483.

Middleton, J. R., D. Hardin, B. Steevens, R. Randle, and J. W. Tyler. 2004. Use of somatic cell counts and California Mastitis Test results from individual quarter milk samples to detect subclinical intramammary infection in dairy cattle from a herd with a high bulk tank somatic cell count. J. Am. Vet. Med. Assoc. 224:419-423.

NMC (National Mastitis Council). 1999. Microbiological Procedures for the Diagnosis of Bovine Udder Infection. 3rd ed. National Mastitis Council, Arlington, VA.

Nickerson, S. C. 1989. Immunological aspects of mammary involution. J. Dairy Sci. 72:1665-1678.

Olde Riekerink, R. G. M., H. W. Barkema, and H. Stryhn. 2007. The effect of season on somatic cell count and the incidence of clinical mastitis. J. Dairy Sci. 90:1704-1715.

Paape, M. J., W. P. Wergin, A. J. Guidry, and R. E. Pearson. 1979 Leukocytes - Second line of defense against invading mastitis pathogens. J. Dairy Sci. 62:135-153.

Passing, H., and W. Bablok. 1983. A new biometrical procedure for testing the equality of measurements from two different analytical methods. Application of linear regression procedures for method comparison studies in clinical chemistry, Part I. J. Clin. Chem. Clin. Biochem. 21:709-720.

Pilla, R., M. Malvisi, G. Snel, D. Schwarz, S. König, C. P. Czerny, and R. Piccinini. 2013. Differential cell count as an alternative method to diagnose dairy cow mastitis. J. Dairy Sci. 96:1653-1660.

Pilla, R., D. Schwarz, S. König, and R. Piccinini. 2012. Microscopic differential cell counting to identify inflammatory reactions in dairy cow quarter milk samples. J. Dairy Sci. 95:4410-4420.

Prasad, L. B. M., and F. H. S. Newbould. 1968. Arylesterase activity of milk from normal and experimentally infected bovine mammary glands. Can. Vet. J. 9:230-236.

Pyörälä, S. 2003. Indicators of inflammation in the diagnosis of mastitis. Vet. Res. 34:565-578.
Salvador, R. T., R. L. Soliven, E. J. Y. Balagan, N. S. Abes, C. A Gutierrez, and C. N. Mingala. 2014. Evaluation of a portable somatic cell counter in the diagnosis of bubaline subclinical mastitis. J. Agric. Sci. 47:205-209.

Sargeant, J. M., K. E. Leslie, J. E. Shirley, B. J. Pulkrabek, and G. H. Lim. 2001. Sensitivity and specificity of somatic cell count and California Mastitis Test for identifying intramammary infection in early lactation. J. Dairy Sci. 84:2018-2024.

Sarikaya, H., and R. M. Bruckmaier. 2006. Importance of the sampled milk fraction for the prediction of total quarter somatic cell count. J. Dairy Sci. 89:4246-4250.

Schalm, O. W., and D. O. Noorlander. 1957. Experiments and observations leading to development of the California mastitis test. J Am. Vet. Med. Assoc. 130:199-204.

Schepers, A. J., T. J. Lam, Y. H. Schukken, J. B. Wilmink, and W. J. Hanekamp. 1997. Estimation of variance components for somatic cell counts to determine thresholds for uninfected quarters. J. Dairy Sci. 80:1833-1840.

Schukken, Y. H., D. J. Wilson, F. Welcome, L. Garrison-Tikofsky, and R. N. Gonzalez. 2003. Monitoring udder health and milking quality using somatic cell counts. Vet. Res. 34:579-596.

Schwarz, D., U. S. Diesterbeck, S. König, K. Brügemann, K. Schlez, M. Zschöck, W. Wolter, and C.-P. Czerny. 2011a. Flow cytometric differential cell counts in milk for the evaluation of inflammatory reactions in clinically healthy and subclinically infected bovine mammary glands. J. Dairy Sci. 94:5033-5044.

Schwarz, D., U. S. Diesterbeck, S. König, K. Brügemann, K. Schlez, M. Zschöck, W. Wolter, and C.-P. Czerny. 2011b. Microscopic differential cell counts in milk for the evaluation of inflammatory reactions in clinically healthy and subclinically infected bovine mammary glands. J. Dairy Res. 78:448-455.

Swets, J. A. 1988. Measuring the accuracy of diagnostic systems. Science 240:1285-1293.

Viguier, C., S. Arora, N. Gilmartin, K. Welbeck, and R. O'Kennedy. 2009. Mastitis detection: Current trends and future perspectives. Trends Biotechnol. 27:486-493.

Wellnitz, O., M. G. Doherr, M. Woloszyn, and R. M. Bruckmaier. 2009. Prediction of total quarter milk somatic cell counts based on foremilk sampling. J. Dairy Res. 76:326-330.

Williams, F. M. 1985. Clinical significance of esterases in man. Clin. Pharmacokinet. 10:392-403. 